\title{
Correspondence
}

\section{Oesophageal pressure measurements in ventilated preterm babies}

Sir,

Drs Greenough and Morley $^{1}$ conclude that very little ventilator pressure is transmitted to the oesophageal balloon in paralysed babies because of low lung compliance, and support this by showing lack of transmission to chest drains inserted in 2 babies with pneumothorax. Although this fits well with their other observations, they did not say whether there was any intrapleural air remaining on the chest $x$-ray film at the time of recording. The compliance of an isolated sealed pocket of air under pressure, say in the mediastinum, could be lower than either lungs or chest wall and could provide a significant artefact in their results.

\section{Reference}

1 Greenough A, Morley CJ. Oesophageal pressure measurements in ventilated preterm babies. Arch Dis Child 1982; 57: $851-5$.

Jo Poulton

John Radcliffe Hospital, Headington, Oxford $O X 39 D U$

Sir,

The study of Greenough and Morley ${ }^{1}$ is interesting in more than one aspect. To our knowledge Fig. $2^{1}$ of that paper is the first demonstration by means of intrapleural pressure recording of the inspiratory augmenting or Head's reflex ${ }^{2}{ }^{3}$ in ventilated preterm infants.

The Head's reflex has been described in newborn infants mainly in association with the first breath. ${ }^{4}$ The influence of gestational age both on Head's reflex and the inspiratory inhibitory reflex (Hering-Breuer reflex) has recently been reviewed by Trippenbach. ${ }^{6}$ In our experience preterm infants are not only more likely to accept rhythmic inflation, but also respond with better inspiration. This is shown by the impedance pneumatogram of an infant of 29 weeks' gestational age on intermittent mandatory ventilation (Figure) and in Fig. 2 of
Greenough and Morley's paper. We seldom observed an enhanced inspiration pattern in a near term or term infant. More often the term infant is fighting against the ventilator, because of a more active Hering-Breuer reflex. Apart from gestational age, however, the low flow rate (5 1/min) used by Greenough and Morley might account for the elicitation of the paradoxical sigh, so nicely shown in that study.

The response of some preterm infants to intermittent mandatory volume ventilation by augmented inspiration bears some practical implications in neonatal respiratory care. In addition to the temporary increase in the functional residual capacity ${ }^{7}$ it offers further arguments for the usefulness of intermittent mandatory ventilation and the limited benefit offered by a synchronised mandatory ventilation modus. Furthermore, the Head's reflex in conjunction with intermittent mandatory ventilation neutralises the negative influences of positive pressure ventilation on the circulation. Finally, it explains why, in some instances, curarisation has a deleterious effect on the oxygenation of the preterm ventilated infant. ${ }^{8}$

The technique suggested by Greenough and Morley will help to define the equivocal clinical concept of 'fighting against the ventilator'. More studies are needed to determine the optimal conditions (flow-rate, peak pressure, etc) to elicit the Head's reflex in ventilated preterm infants.

\section{References}

1 Greenough A, Morley CJ. Oesophageal pressure measurements in ventilated preterm babies. Arch Dis Child 1982; 57: $851-5$.

2 Head H. On the regulation of respiration. J Physiol 1889; 10: 1-70.

3 Widdicombe JG. Head's paradoxical reflex. $Q J$ Exp Physiol 1967; 52: 44-50.

4 Cross KW, Klaus M, Tooley WH, Weisser K. The response of the new-born baby to inflation of the lungs. J Physiol 1960; 151 : 551-65.

5 Boon AW, Milner AD, Hopkin IE. Physiological responses of the newborn infant to resuscitation. Arch Dis Child 1979; 54: 492-8.

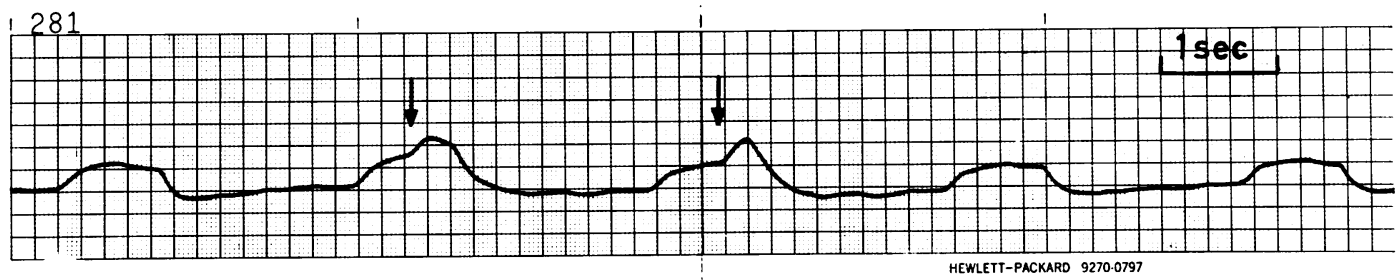

Figure Impedance pneumatogram of a 29 weeks' gestational age newborn infant ventilated on intermittent mandatory ventilation modus (flow rate $5 \mathrm{l} / \mathrm{min}$ ). The enhanced inspiration (arrows) in two out of five inflations is clearly seen. The observation can be done with the use of routine clinical monitoring equipment. 